\title{
LA-UR- $90=9$
}

Approved for public release; distribution is unlimited.

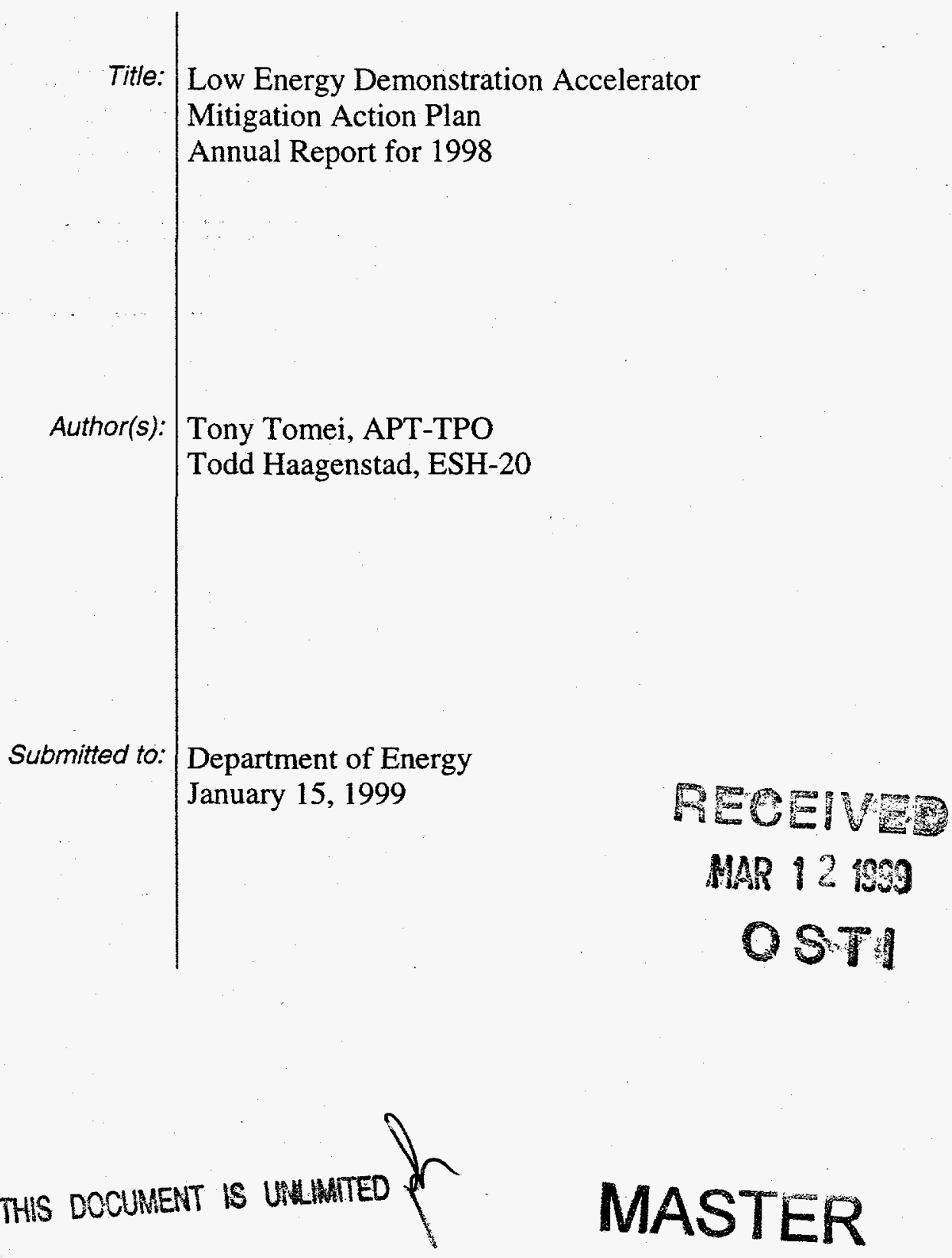

\section{Los Alamos} NATIONAL LABORATORY

Los Alamos National Laboratory, an affirmative action/equal opportunity employer, is operated by the University of California for the U.S. Department of Energy under contract W-7405-ENG-36. By acceptance of this article, the publisher recognizes that the U.S. Government retains a nonexclusive, royalty-free license to publish or reproduce the published form of this contribution, or to allow others to do so, for U.S. Government purposes. Los Alamos National Laboratory requests that the publisher identify this article as work performed under the auspices of the U.S. Department of Energy. Los Alamos National Laboratory strongly supports academic freedom and a researcher's right to publish; as an institution, however, the Laboratory does not endorse the viewpoint of a publication or guarantee its technical correctness. 


\section{DISCLAIMER}

This report was prepared as an account of work sponsored by an agency of the United States Government. Neitber the United States Government nor any ageacy thereof, nor any of their employees, makes any warranty, expross or implied, or assumes any legal liability or responsibility for the accuracy, completeress, or usefulness of any information, apparatus, product, or process disclosed, or represents that its use would not infringe privately owned rights. Reference berein to any specific commercial product, process, or service by trade name, trademart, inanufacturer, or otherwise does not necessarily constitute or imply its endorsement, recom. mendation, or favoring by the United States Government or any ageacy thereof. The views and opinions of authors expresed herein do not neceasarily state or reflect those of the United States Government or any agency thereof. 


\section{DISCLAIMER}

Portions of this document may be illegible in electronic image products. Images are produced from the best available original document. 


\section{TABLE OF CONTENTS}

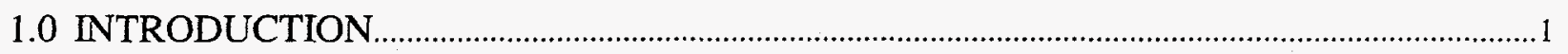

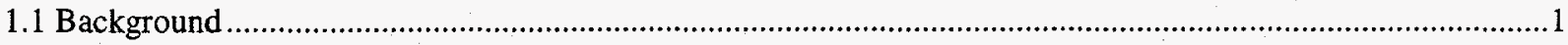

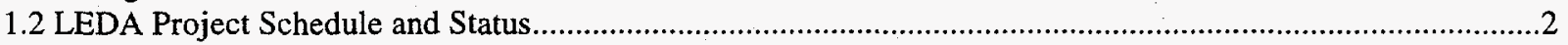

2.0 LEDA MAP SCOPE AND STATUS ..................................................................... 4

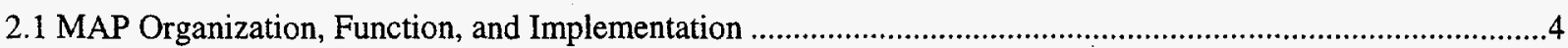

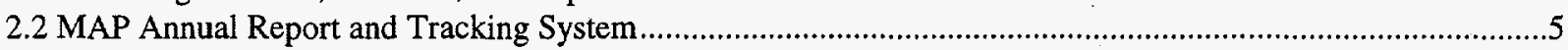

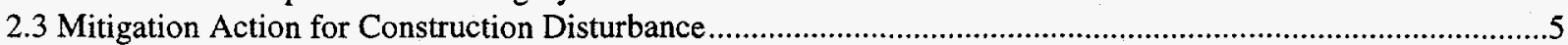

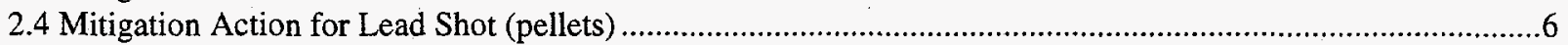

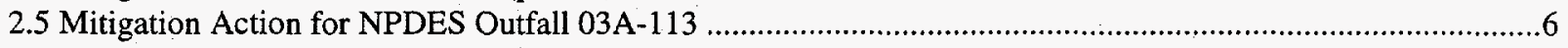

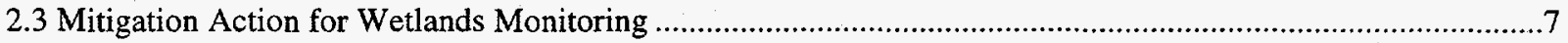

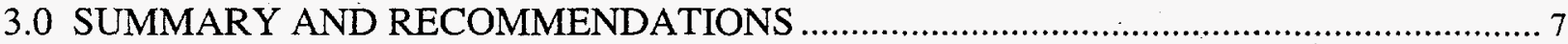

Table 1-1: Original LEDA Project Stages and Schedule .............................................................................

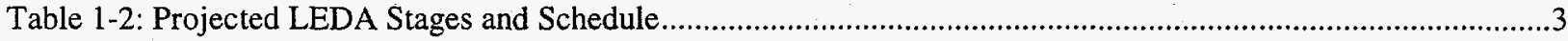

Table 2-1: Mitigation Action Commitments and Status................................................................................4 


\section{$1.0 \quad$ INTRODUCTION}

This Mitigation Action Plan Annual Report (MAPAR) has been prepared by the U.S. Department of Energy (DOE) as part of implementing the Low Energy Demonstration Accelerator Facility (LEDA) Mitigation Action Plan (MAP). This MAPAR primarily provides a status on specific LEDA facility construction- and operations-related mitigation actions that have been implemented during 1998. The mitigation actions are implemented in order to comply with regulatory requirements under the National Environmental Policy Act (NEPA) by fulfilling DOE's commitments under the LEDA MAP.

This report contains the following three main sections: Introduction; LEDA MAP scope, schedule, and status; and Summary and Recommendations. The Introduction section provides a background regarding the origin and purpose of the LEDA MAP. The LEDA MAP scope, schedule, and status section provides a more detailed description of each mitigation action commitment and the current status of each associated action plan. Finally, the Summary and Recommendations section provides DOE's recommendation regarding future implementation based on the status of each commitment action plan.

\subsection{Background}

As part of DOE's need to maintain the capability of producing tritium in support of its historic and near-term stewardship of the nation's nuclear weapons stockpile, in 1995 the agency completed a programmatic Environmental Impact Statement (PEIS) for Tritium Supply and Recycling (TRS). The resulting Record of Decision (ROD) issued December 5, 1995, established a strategy to pursue both nuclear reactor and accelerator technologies for tritium production (DOE 1995). In support of this DOE strategy, Los Alamos National Laboratory (LANL) has actively pursued the accelerator technology component of the strategy through an Accelerator Production of Tritium (APT) program. A key component of the APT program is the LEDA project. The LEDA project is a mull-year and multi-stage DOE project that investigates the design and reliability of components and operations needed for a full-scale APT system. The LEDA project is conducted in an accelerator research facility. The LEDA facility is used to design, build, and test components of a prototype low-energy linear (linac) accelerator that may be used as the basis for the design, construction, and operation of a full-scale APT plant elsewhere within the DOE complex.

In April 1996, the DOE published a Final Environmental Assessment (EA) for the LEDA facility at LANL, DOE/EA-1147. This EA was prepared according to NEPA regulations established by the Council on Environmental Quality (42 U.S.C. 4321 et seq. of 1969; 40 CFR Part 1500-1508). The LEDA EA analyzed the potential environmental effects associated with a proposed action to construct and operate the LEDA facility at LANL. The following issues were evaluated for the proposed action: utility demands, air, human health, environmental restoration, waste management, transportation, water, threatened and endangered species, wetlands, cultural resources, and environmental justice (DOE 1996). 
The EA analysis indicated that potential adverse effects of the proposed action under normal operating conditions would be minimal. The EA analysis did, however, indicate that four potential adverse effects could be caused by constructing and operating the LEDA facility. The potentially adverse effects are primarily associated with construction disturbance and the anticipated LEDA facility use of an existing National Pollutant Discharge Elimination System (NPDES) Outfall. These four potential adverse effects are as follows:

1. Depending upon the final design plan for LEDA utility construction, over five (5) acres of soil could be disturbed. Storm events could initiate buildups of silt form the disturbed area in the streambeds of both Sandia and Los Alamos Canyons.

2. LANL's Environmental Restoration (ER) project identified and area of lead shot (pellets) located immediately down gradient of NPDES Outfall 03A-133 and partly within its drainage channel. Increased discharges to the outfall could spread the lead shot (pellets) and potentially spread lead contamination.

3. Increased discharge from the LEDA facility could potentially cause erosion problems in the drainage channel leading from Outfall 03A-133 to Sandia Canyon.

4. The projected Stage V effluent discharges from the LEDA facility could potentially cause formation of a wetland at the confluence of Sandia Canyon and the drainage channel for NPDES Outfall 03A-113.

With the final EA, DOE published a Finding of No Significant Impact (FONSI) and a Mitigation Action Plan (MAP). The LEDA FONSI documents DOE's decision to conduct the LEDA project and also summarizes the potential impacts associated with constructing and operating the LEDA facility at LANL (DOE 1996). The LEDA MAP further documents the potential adverse environmental effects identified in the LEDA EA that could result from the pursuit of the LEDA project as identified in the FONSI. Finally, the MAP identifies commitments made in the FONSI to mitigate those effects and establishes action plans for implementing each mitigation commitment (DOE 1996).

\subsection{LEDA Project Schedule and Status}

The long-term objective of the LEDA project is to design, build, and test critical prototype lowenergy front-end components of an accelerator system for tritium production. The prototype accelerator is intended to be incrementally developed and tested in five separate stages (Stages IV) over seven years (1996-2002). The near-term project objective (1996-1999) has been to complete Stage II and a substantial portion of Stage III prior to an anticipated DOE programmatic decision regarding the primary tritium production option as defined in the TRS PEIS ROD. Table 1-1 provides and overview of the originally projected LEDA project schedule. 
Table 1-1: Original LEDA Project Stages and Schedule

\begin{tabular}{|c|c|c|c|c|c|}
\hline Stage & Configuration & $\begin{array}{c}\text { Proton Beam } \\
\text { Energy (MeV) }\end{array}$ & $\begin{array}{c}\text { Installation } \\
\text { Begins }^{\mathbf{1}}\end{array}$ & $\begin{array}{c}\text { Experiment } \\
\text { Begins }^{1}\end{array}$ & $\begin{array}{c}\text { Expected } \\
\text { Duration } \\
\text { (months) }\end{array}$ \\
\hline $\begin{array}{c}\text { Initial } \\
\text { Preparation }\end{array}$ & Under design & NA & NA & NA & 12 \\
\hline I & Injector only & 0.075 & October 1996 & April 1997 & 7 \\
\hline II & Injector + RFQ & 7 & April 1997 & November 1997 & 8 \\
\hline III & $\begin{array}{c}\text { Injector + RFQ + one 20 } \\
\text { MeV CCDTL }\end{array}$ & 20 & March 1998 & July 1998 & 15 \\
\hline IV & $\begin{array}{c}\text { Injector + RFQ + one 40 } \\
\text { MeV CCDTL }\end{array}$ & 40 & December 1998 & October 1999 & 11 \\
\hline V & $\begin{array}{c}2 \text { Injectors + 2 RFQs + two } \\
20 \text { MeV CCDTLs + Funnel } \\
+ \text { another CCDTL }\end{array}$ & $30-40$ & December 1999 & September 2000 & 31 \\
\hline
\end{tabular}

1 These are the earliest possible dates

2 Radio-frequency quadruple

3 Coupled-cavity drift-tube linac

The schedule for the LEDA project has been modified since the issuance of the FONSI. In 1996, the original project schedule was scaled back and continued in this mode during 1997. The scaled-back schedule limited stage development in 1996 as well as in 1997. A Safety Analysis Document (SAD) has been written for LEDA and was approved by DOE on June 5, 1998. The SAD is used to establish the safety-specific operating envelope for the LEDA facility, and only covers R\&D activities through Stage III. There is a remote possibility that Stage IV would be developed in the future, but this would require a re-write of the SAD to allow for Stage IV construction and operation. In 1996 Stage V was removed from the LEDA project schedule and is will not be included in the future LEDA work at LANL. The present work at LANL assumes Stage III will be the last stage developed. Table 1-2 provides an overview of the current LEDA project schedule.

Table 1-2: Projected LEDA Stages and Schedule

\begin{tabular}{|c|c|c|c|c|c|}
\hline Stage & Configuration & $\begin{array}{c}\text { Proton Beam } \\
\text { Energy (MeV) }\end{array}$ & $\begin{array}{c}\text { Installation } \\
\text { Begins }^{1}\end{array}$ & $\begin{array}{c}\text { Experiment } \\
\text { Begins }\end{array}$ & $\begin{array}{c}\text { Expected } \\
\text { Duration } \\
\text { (months) }\end{array}$ \\
\hline $\begin{array}{c}\text { Initial } \\
\text { Preparation }\end{array}$ & $\begin{array}{c}\text { Design completed CY96- } \\
97\end{array}$ & NA & NA & NA & 12 \\
\hline I & Injector only & 0.075 & FY97 & FY98 & 7 \\
\hline II & Injector + RFQ & & FY98 & 18 \\
\hline III & $\begin{array}{c}\text { Injector + RFQ + one 20 } \\
\text { MeV CCDTL }\end{array}$ & 12 max & FY98 & November 1998 & TBD $^{4}$ \\
\hline $\begin{array}{c}\text { IV } \\
\text { May be } \\
\text { developed }\end{array}$ & $\begin{array}{c}\text { Injector + RFQ + one 40 } \\
\text { MeV CCDTL }\end{array}$ & Unknown & Unknown & Unknown & Unknown \\
\hline
\end{tabular}

1 These are the earliest possible dates

2 Radio-frequency quadruple

3 Coupled-cavity drift-tube linac

4 To be determined 
On December 24, 1998, the DOE Secretary Bill Richardson fulfilled the 1995 TRS PEIS ROD commitment to select between a commercial light reactor and a linear accelerator as the primary source of tritium by the end of 1998. The Secretary of Energy selected commercial light reactor technology and, consistent with DOE's dual track strategy for tritium production, the linear accelerator option has been designated as a backup technology. The DOE will complete key research and development milestones for the accelerator technology as defined by the current LEDA project scope and schedule.

\subsection{LEDA MAP SCOPE AND STATUS}

\subsection{MAP Organization, Function, and Implementation}

The LEDA MAP was prepared and issued by DOE on April 1, 1996. The function of the LEDA MAP is to document potential adverse environmental effects that could result from pursuit of the LEDA project, identify commitments made in the FONSI to mitigate those effects, and to establish Action Plans to carry out each commitment together with the responsible DOE or LANL contractor organization. The LEDA project management, in cooperation with the ESH-20 group leader, are responsible overall for conducting the mitigation measures performed either by their personnel (or subcontractors), and for data collection and monitoring activities performed by ESH-20 and other LANL personnel. DOE has overall responsibility for insuring the adequate and timely completion of all actions associated with the MAP. The day-to-day MAP implementation activities are coordinated by ESH-20 in collaboration with the LEDA project management.

The LEDA EA provided the basis for the scope of the LEDA MAP. The LEDA EA identified four potential adverse effects associated with the construction and operation of the LEDA facility. Although the scope of the existing LEDA project is limited to Stage III, the scope of the EA analysis included construction and operations through Stage V. Due to the reduced scope of the current LEDA project, the EA provides an "over-estimation" of the potential adverse effects. Along with the Mitigation Tracking System (MTS), these four potential adverse effects comprise the basis for the scope of the mitigation action commitments implemented under the LEDA MAP; Table 2-1 summarizes the issues and potential effects, mitigation action commitments, and the current status of each mitigation action.

Table 2-1: Mitigation Action Commitments and Status

\begin{tabular}{|l|l|l|}
\hline \multicolumn{1}{|c|}{ Issue; potential effect } & Mitigation Action Commitment & \multicolumn{1}{c|}{ Status of Mitigation } \\
\hline $\begin{array}{l}\text { LEDA construction: more than } \\
\text { five acres of soil disturbance } \\
\begin{array}{l}\text { could results in build up of silt } \\
\text { in stream beds within Sandia } \\
\text { and Los Alamos Canyons } \\
\text { during storm events. }\end{array}\end{array}$ & $\begin{array}{l}\text { LANL will develop a SWPP Plan in } \\
\text { the event that more than five acres } \\
\text { of soil are disturbed during LEDA } \\
\text { construction. }\end{array}$ & $\begin{array}{l}\text { The LEDA project activities during } \\
1998 \text { resulted in less than one (1) } \\
\text { acre of soil disturbance and a SWPP } \\
\text { Plan was not required. }\end{array}$ \\
\end{tabular}


Table 2-1: Mitigation Action Commitments and Status (contined)

\begin{tabular}{|c|c|c|}
\hline $\begin{array}{l}\text { Lead shot (pellet) contamination: } \\
\text { LEDA effluent discharge could } \\
\text { potentially spread lead shot } \\
\text { (pellet) contamination within } \\
\text { drainage channel of Outfall } \\
\text { 03A-113. } \\
\end{array}$ & $\begin{array}{l}\text { LANL will remove lead shot } \\
\text { (pellet) contamination prior to } \\
\text { discharge of LEDA effluent. }\end{array}$ & $\begin{array}{l}\text { The lead shot (pellet) contamination } \\
\text { within the drainage channel of } \\
\text { Outfall 03A-113 was removed in } \\
1996 .\end{array}$ \\
\hline $\begin{array}{l}\text { Outfall 03A-113 discharge: } \\
\text { increased discharge from } \\
\text { Outfall } 03 \mathrm{~A}-113 \text { could result in } \\
\text { additional erosion of drainage } \\
\text { channel into Sandia Canyon. }\end{array}$ & $\begin{array}{l}\text { LANL will monitoring NPDES } \\
\text { Outfall 03A- } 113 \text { on a quarterly } \\
\text { basis to ensure the discharge meets } \\
\text { the requirements of LANL's } \\
\text { NPDES permit, and that necessary } \\
\text { best management practices are } \\
\text { implemented as needed. }\end{array}$ & $\begin{array}{l}\text { The quarterly monitoring of Outfall } \\
03 \mathrm{~A}-113 \text { indicated only slight } \\
\text { erosion of the drainage channel. } \\
\text { During } 1998 \text { the NPDES maximal } \\
\text { allowable limits for monitored } \\
\text { chemicals were not exceeded. }\end{array}$ \\
\hline $\begin{array}{l}\text { Monitoring wetland development: } \\
\text { increased discharge from } \\
\text { Outfall 03A-113 could } \\
\text { potentially form a wetland in } \\
\text { Sandia Canyon. }\end{array}$ & $\begin{array}{l}\text { If a wetland forms, LANL will } \\
\text { conduct further biological } \\
\text { evaluation and wetland monitoring. } \\
\text { NEPA analyses and wetland } \\
\text { regulatory compliance evaluation } \\
\text { will be conducted by DOE before } \\
\text { flow to wetland from NPDES } \\
\text { Outfall 03A-113 is eliminated. }\end{array}$ & $\begin{array}{l}\text { Biological monitoring was } \\
\text { completed in } 1996 \text { and } 1997 . \\
\text { Based on monitoring data and } \\
\text { knowledge of current LEDA project } \\
\text { scope, wetlands formation has been } \\
\text { confirmed as highly unlikely under } \\
\text { the current conditions. }\end{array}$ \\
\hline
\end{tabular}

\subsection{MAP Annual Report and Tracking System}

Activities associated with LEDA MAP implementation were originally required to be reported in a MAPAR to be issued by April 1 for the preceding calendar year, beginning one year after LEDA project construction activities were initiated. The DOE Los Alamos Area Office changed this reporting cycle to January 15 in order to align the reporting cycle with the fiscal year funding cycle. The MAPAR must be continued annually thereafter, until the completion of the LEDA project. The MAPAR must reflect new information or changed circumstances and must be used as the basis for documenting the progress of fulfilling commitments described in the MAP through the DOE MTS. A Completion Report will be issued by the DOE at the time of completion of all mitigations. This MAPAR represents a summary of the third full year of LEDA MAP implementation.

\subsection{Mitigation Action for Construction Disturbance}

\section{Potential Environmental Effect:}

Depending upon the final design for LEDA utility construction, over five (5) acres of soil could be disturbed. Storm events could initiate buildups of silt from the disturbed area in the streambeds of both Sandia and Los Alamos Canyons.

\section{Mitigation Action Commitment:}

If LEDA facility construction results in five or more acres of disturbance, the LEDA MAP requires the implementation of a Storm Water Pollution Prevention (SWPP) Plan during the LEDA construction period and appropriate re-vegetation of the disturbed site afterwards. 
Mitigation Status:

The LEDA project activities during 1998 resulted in less than one (1) acre of soil disturbance for construction of utilities. The initial LEDA project activities were performed in an existing building at LANL. Due to the limited amount of construction disturbance a SWPP Plan was not required in 1998.

\subsection{Mitigation Action for Lead Shot (pellets)}

\section{Potential Environmental Effect:}

LANL's Environmental Restoration (ER) project identified an area of lead shot (pellets) located immediately down gradient of NPDES Outfall 03A-113 and partly within its drainage channel. Increased discharges to the outfall could spread the lead shot (pellets) and potentially spread lead shot contamination.

\section{Mitigation Action Commitment:}

Before water from the LEDA project is released through NPDES Outfall 03A-113, the LEDA MAP requires the removal of the lead shot (pellets) area immediately down gradient of the outfall.

\section{Mitigation Status:}

As indicated in previous LEDA MAPARs, the lead shot (pellet) contamination within the drainage channel of Outfall 03A-113 was removed in 1996 prior to releasing LEDA facility effluent.

\subsection{Mitigation Action for NPDES Outfall 03A-113}

\section{Potential Environmental Effect:}

Increased discharges from LEDA could potentially cause erosion problems in the drainage channel leading from NPDES Outfall 03A-113 to Sandia Canyon.

\section{Mitigation Action Commitment:}

The MAP requires LANL to conduct quarterly monitoring of NPDES Outfall 03A-113. Quarterly monitoring must be performed by LANL's Hydrology Group (ESH-18) personnel to ensure the discharge meets the requirements of LANL's NPDES permit. At the same time, the drainage channel of the outfall must also be monitored for erosion effects. If needed, appropriate erosion controls will be implemented by the LEDA project management employing best management practices.

\section{Mitigation Status:}

The NPDES Outfall 03A-113 is permitted and is monitored for effluent chemical composition and flow on a quarterly basis by LANL's Hydrology Group, ESH-18. Total suspended solids, phosphorus, arsenic, and chlorine are also monitored by ESH-18 at the outfall. Water monitoring at the outfall has been done since the inception of the LEDA project. Effluent monitoring was conducted during 1998 and will continue for the duration of the LEDA project. The LEDA project effluent was discharged through the existing cooling water tower at building MPF-365 through November 1998. In December 1998, a new cooling tower located just west of MPF-365 
was brought into service. The effluent volume increased slightly due to an increase in cooling water needs for developing Stage I, and the increased size of the new cooling tower. The amount of water discharged through this outfall has not changed significantly since the late 1980s and additional best management practices have not been required. The rock drainage channel of NPDES Outfall 03A-113 has been monitored and was only slightly eroded by the effluent and precipitation flow during 1998. During 1998 the NPDES maximum allowable limits for monitored chemicals were not exceeded.

\subsection{Mitigation Actions for Wetland Monitoring}

\section{Potential Environmental Effect:}

Increased discharges from LEDA could potentially cause formation of a wetland at the confluence of Sandia Canyon and the drainage channel for NPDES Outfall 03A-113.

\section{Mitigation Action Commitment:}

In the unlikely event that a wetland forms in Sandia Canyon by the end of the LEDA project, the LEDA MAP requires that further biological evaluation by the ESH-20 must be performed. Appropriate NEPA analyses and wetland regulatory compliance evaluation would have to be conducted by DOE before flow to Outfall 03A-113 was eliminated.

\section{Mitigation Status:}

Based on the previous biological monitoring and knowledge of the current LEDA project schedule, it is highly unlikely that a wetland will be formed in Sandia Canyon from LEDA effluent. The LEDA project is currently anticipated to be implemented through Stage III. According to the LEDA EA, Stage III will use about one-third as much water as the amount projected for LEDA Stage V. In the LEDA EA, the project Stage V water use was used as the "bounding case" for analyzing the potential formation of a wetland from LEDA effluent. As a precaution, in 1996 and 1997 baseline biological and soil data were collected in Sandia Canyon in the vicinity of NPDES Outfall 03A-113. The data were collected to establish a biological baseline in and around the outfall vicinity. The data collected confirmed that the LEDA effluent was not generating a wetland in Sandia Canyon. In the event that the LEDA project proceeds to Stage V or is significantly modified, the need for biological monitoring of the outfall area will be re-evaluated as necessary.

\subsection{SUMMARY AND RECOMMENDATIONS}

In 1996 the original scope of the LEDA project was modified. Under the current project scope, the LEDA project would be implemented through Stage III and would possibly include Stage IV. A SAR (Safety Analysis Report) for project implementation through Stage III has been prepared and was approved by DOE. If the LEDA project proceeds into Stage IV in the future, the SAR would have to be amended before Stage IV project implementation could proceed.

All mitigation commitments under the LEDA MAP are on schedule or complete. The mitigation action for lead shot (pellet) was completed in 1996. The mitigation action for construction disturbance and NPDES Outfall 03A-113 are on schedule. The construction disturbance of the 
LEDA facility site did not exceed five acres during 1998 and a SWPP Plan was not required. The quarterly monitoring of Outfall 03A-113 was completed for 1998, the outfall effluent met all regulatory discharge standards, and no excessive drainage channel erosion was identified. The mitigation commitment for wetland monitoring did not require implementation as conditions for wetland development did not occur.

DOE will continue to implement the LEDA MAP as appropriate. The mitigation commitments for construction disturbance, outfall monitoring, and wetlands monitoring will be implemented as needed based on the scope and status of the LEDA project 


\section{CITATIONS:}

DOE 1995: Programmatic Environmental Impact Statement for Tritium Supply and Recycling, DOE/EIS-0161, October 1995.

DOE 1996: Final Environmental Assessment for the Low Energy Demonstration Accelerator Technical Area 5; Finding of No Significant Impact; and Mitigation Action Plan, DOE/EA-1147, April 1996. 